\title{
Cuerpos en el psiquiátrico, la mirada y la cámara: la locura visible del siglo XIX*
}

\author{
Bodies in the psychiatric, the look and the camera: \\ the visible madness of the 19th century
}

Corpos no psiquiátrico, o olhar e a câmera:

a loucura visível do século XIX

\begin{abstract}
Meira del Busto**
Red de Etnopsiquiatría: Estudios Sociales y de la Cultura

La Colibrí Lab: Investigación, Producción y Medios para Artes

Correo electrónico: meirapaolaba@gmail.com

Revista Corpo-grafías: Estudios críticos de y desde los cuerpos / Volumen 5 - Número 5 / Enero - diciembre de 2018 /

ISSN impreso 2390-0288, ISSN digital 2590-9398 / Bogotá, D.C., Colombia / pp. 221-237.

Fecha de recepción: 30 de julio de 2017

Fecha de aceptación: 10 de agosto de 2017

Doi: https://doi.org/10.14483/25909398.14218

Cómo citar este artículo: Del Busto, M. (2018, enero-diciembre). Cuerpos en el psiquiátrico, la mirada y la cámara: la locura visible del siglo XIX. Revista Corpo-grafías: Estudios críticos de y desde los cuerpos, 5(5), p-p 221-237 / ISSN 2390-0288.

*Artículo de investigación: artículo derivado de la investigación de pregrado desarrollada por la autora, con el Instituto de Investigaciones de la Facultad de Psicología de la Universidad de Buenos Aires, Argentina, en torno al uso de la fotografia por la psiquiatría a finales del siglo XIX en Francia y Estados Unidos. Desde la teoría de la imagen que esbozó Lacan, se leen tres archivos fotográficos develando el carácter teatralizado y ficcional en la construcción de la idea de locura.

**Psicóloga y Magíster en Estudios Artísticos. Se dedica a la investigación-creación en temáticas de la historia cultural asociada a subjetividades excluidas y el video arte. Su trabajo académico se ha centrado en la Cultura Visual en la historia de la psiquiatría. Actualmente dirije La Colibrí Lab: investigación, producción y medios para artes donde desarrolla junto con artistas e investigadores, pensamiento, contenidos y creación en el ámbito de las artes visuales y artes del movimiento en Bogotá, Colombia.
\end{abstract}

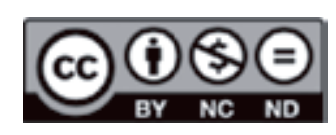




\title{
Resumen
}

La fotografía fue vista como una "emanación mágica", donde quedaría por fin plasmada esa interioridad que antaño era atribuida a la acción de seres intangibles y extraños movimientos del espíritu que producían la locura. En este trabajo, se busca indagar sobre la relación entre el discurso psiquiátrico del siglo XIX y la producción de imágenes, en la constitución de un régimen visual científico. Las fotografías que se traen al análisis, coinciden con el nacimiento de una especie de objetividad mecánica, donde los modos de ver están de lleno mediatizados por la novedad del aparato fotográfico, considerado como aparato informativo, que soporta los procedimientos científicos de demostración, comparación e ilustración sobre el cuerpo del "paciente mental".

Palabras clave: cuerpo ficcionado; enfermedad mental; psiquiatría; fotografía médica; régimen visual.

\begin{abstract}
The photograph was seen as a "magic emanation", where it would be finally captured that interiority that was once attributed to the action of intangible beings and strange movements of the spirit that produced madness. In this work, we seek to investigate the relationship between psychiatric discourse of the 19th century and the production of images, in the constitution of a scientific visual regime. The photographs that are brought to the analysis, coincide with the birth of a kind of mechanical objectivity, where the ways of seeing are fully mediated by the novelty of the photographic apparatus, considered as an informative device that supports the scientific procedures of demonstration, comparison and illustration about the body of the "mental patient".
\end{abstract}

Keywords: fiction body; mental illness; psychiatry; medical photography; visual regime.

\section{Resumo}

A fotografia foi vista como uma "emanação mágica" que finalmente capturado a interioridade que uma vez foi atribuído à ação de seres incorpóreos e movimentos estranhos do espírito que produziu loucura. Destina-se a investigar a relação entre o discurso psiquiátrico do século XIX ea produção de imagens, na criação de um regime visual. As fotografias trazem para análise coincide com o nascimento de um tipo de objetividade mecânica, onde os modos de ver são totalmente mediada pela novidade do aparelho fotográfico, considerado como um sistema de informação, que suporta procedimentos científicos demonstração, comparação e ilustração sobre o corpo de "doente mental".

Palavras chave: corpo ficcionado; doença mental; psiquiatria; fotografia médica; sistema visual. 
Hay un plus de la imagen del que el texto no puede dar cuenta; más aún, cuando ese texto es el texto de la locura.

"La palabra y la imagen ilustran aún la misma fábula de la locura en el mismo mundo moral; pero siguen ya dos direcciones diferentes, que indican, en una hendidura apenas perceptible, lo que se convertirá en la gran línea de separación de la experiencia occidental de la locura.

Michael Foucault, Las palabras y las cosas, (1971)

La psiquiatría durante el siglo XIX presentaba nuevas concepciones epistemológicas sobre las causas de la locura: la producción del conocimiento psiquiátrico refleja las condiciones políticas, económicas y filosóficas propias del proceso positivista en las Ciencias del Hombre. El interés de esta indagación está puesto en el siglo XIX dado que los planteamientos esenciales para entender la locura que se dieron allí son la base epistemológica del concepto de Enfermedad Mental que se mantiene hasta el presente en sus aspectos ideológicos y como eje discursivo de la disciplina psiquiátrica. La locura se hace un objeto de estudio para la ciencia, basada en la explicación de los mecanismos fisiológicos, las localizaciones físicas, los aspectos visibles, la Mirada en este sentido, se convierte en fuente de conocimiento.

Esta perspectiva se traduce en la formulación de categorizaciones, nosologías y cuadros patológicos empleados en la actualidad como recurso de organización y manejo de la Enfermedad Mental. Una relación insoslayable con esta concepción, se da con la palabra escrita, la descripción, y las formas creadas por el lenguaje, en la búsqueda de dar un lugar en lo imaginario a lo inextricable de la locura. Esta relación entre cuerpo y palabra, entre la imagen y la cosa, atraviesa los intentos de categorizar el mundo, de dar palabra a lo irrepresentable. Ese esfuerzo, se apoya en las técnicas para ver, y se instrumentaliza el campo de la Mirada por la acción de entrenamientos, regularidades y habilidades que se supone aseguran un operar objetivo sobre lo visto: una suerte de dominio y reducción.

La invención de la fotografía durante el siglo XIX, amplía las capacidades del ojo humano para ver y es vinculada a la veracidad, en el contexto de una sociedad ávida del desciframiento de los nuevos mundos, de la diferencia que plantea el encuentro con el otro, de la fascinación por el exotismo de lo desconocido. La representación de lo diferente da lugar al enorme peso de lo imaginario y lo fantástico, componente que animó a toda una sociedad a confiar en la imagen, a imaginar desde la producción visual.

Foucault (1964) conceptualiza tres invenciones-enfermedades del pensamiento psiquiátrico en el siglo XIX que constituyeron la organización de la experiencia de la locura y que planteaban un giro fundamental respecto de su percepción en la época clásica: la invención de la Parálisis general, la locura moral y la monomanía. Estas constituyeron una reorganización del espacio nosográfico, donde el loco se convierte en centro de la problemática de la verdad del hombre, donde la locura se convierte en la antítesis perfecta de donde el hombre podrá definir la luz que lo envuelve:

El hombre y el loco están ligados en el mundo moderno más sólidamente quizá de lo que pudiesen estarlo en las poderosas metamorfosis animales antaño iluminadas por los molinos incendiados del Bosco: están atados por ese vínculo impalpable de una verdad recíproca e incompatible; se dicen uno al otro esta verdad de su esencia que desaparece al haber sido dicha por el uno al otro. 
Esta luz que emerge de las sombras, va a posicionar un nuevo eje de explicación de la sin-razón que pareciera sustraer en alguna medida los vínculos fantásticos, espirituales, metafísicos, que funcionaron como ejes en la época clásica. Ahora es posible una localización: es el Cuerpo ese volumen en el cual se va a poder localizar la enfermedad, es lo visible el lugar que emana la claridad de una posible explicación del hombre, es en su aspecto más superficial, donde se exhibe ante la mirada, el lugar de la objetivación que lo hace comprensible, medible y comparable:

Durante el periodo clásico, la trascendencia del delirio aseguraba la locura, por manifiesta que fuese, una especie de interioridad que no afloraba nunca al exterior, que la mantenía en una relación irreductible consigo misma. Ahora toda locura y el todo de la locura deberán tener su equivalente externo; o, mejor dicho, la esencia misma de la locura consistirá en objetivar al hombre, en arrojarlo al exterior de sí mismo, en exponerlo finalmente al nivel de una naturaleza pura y sencilla, al nivel de las cosas. (Foucault, 1964, p. 139)

\section{Cuerpos revelados}

Este giro visual-científico, re interpreta radicalmente la locura, que siempre había sido un objeto evanescente, esquivo a la racionalidad y cercana a lo mágico. Este nuevo posicionamiento, emerge en el siglo XIX con su correlato a nivel representativo, la locura se podrá escribir. Si el centro de la explicación de la locura es localizable, entonces tendrá su correlato en la imagen:

Desde los primeros años del siglo XIX, las ilustraciones de la enfermedad mental empezaron a complementar o reemplazar las descripciones verbales de la enfermedad en la literatura médica sobre la locura. (...) Este cambio se evidencia en el uso de ilustraciones que Pinel hace en su Medico-philosophical Treatise in Mental Alienation, or Mania, publicado en 1801. Que comprende la adopción de una aproximación estrictamente empírica a los hechos científicos y que insiste sobre la capacidad del lector de observar directamente los casos bajo discusión. (Jackson, 1995, p.325)

La fotografía fue vista como una "emanación mágica", donde quedaría por fin plasmada esa interioridad que antaño era atribuida a la acción de seres intangibles y extraños movimientos del espíritu. En el siglo XIX la locura se expresa en la invención de un caso, el origen de la noción de enfermo mental se deriva de la posibilidad de hacer visible esa interioridad que hace preguntas a la verdad del hombre a través de su negatividad. La pregunta que guía esta reflexión es poder relacionar la emergencia del discurso psiquiátrico y la producción visual científica. De qué forma las imágenes fotografías expresan y sirven de justificación de las ideas psiquiátricas. La elección de las fotografías que se traen al análisis, coinciden con el nacimiento de una especie de objetividad mecánica, donde los modos de ver están de lleno mediatizados por la novedad del aparato fotográfico, considerado como aparato informativo.

La forma en que la psiquiatría incorporó la fotografía se inspira en los usos que de ella hicieron la antropología y la criminología: producir imágenes múltiples que permitieran la comparación, la demostración, y la ilustración de nuevos hallazgos. La elaboración de archivos al interior de los hospitales psiquiátricos, tenía esta misma función de asegurar el registro y control de los pacientes, a la vez que fue vista como un instrumento de pronóstico clínico; en esta clínica de la imagen en la cual las manifestaciones del cuerpo venían a corresponderse con un estado patológico. Hugh W. Diamond fue uno de los primeros psiquiatras en hacer uso de la fotografía como herramienta que 
permitiera retratar a los pacientes para posteriormente asignarles una categoría patológica, dependiendo de unos rasgos observables en la imagen, tal como era planteado por las teorías fisiognómicas.

Las imágenes que han servido a esta reflexión fueron tomadas de dos archivos fotográficos producidos en el siglo XIX: dos de ellos fueron registrados en el Hospital de la Salpêtrière en Paris. El tercero corresponde al álbum fotográfico realizado por Joseph Parris en New Jersey, denominado Fotografías de Pacientes del manicomio de imbéciles, con fecha aproximada, 1886. Existen versiones digitales de estos archivos efectuados por las mismas instituciones hospitalarias o como parte de bases de datos de patrimonio. La división de los archivos marca así mismo una primera categoría con la que se intenta pensar cómo opera la invención de la enfermedad sobre un cuerpo, es el cuerpo la superficie que se intenta captar aquí con la fotografía, pero en cada caso encontramos una organización, una retórica y puesta en escena distinta. En principio, la identidad de las personas fotografiadas no es valorada como dato relevante. En general, pareciera entenderse que la imagen habla por sí misma, no se transcriben nombres, edad u origen. Más bien se utilizan descripciones genéricas como Paciente de Asilo.

La organización propuesta tiende a poner de manifiesto cómo se presenta este cuerpo del loco en la fotografía, en el modo en que hay un diseño del cuerpo allí planteado desde lo visual. Aunque estos cuerpos correspondan a archivos fotográficos localizados en distintas fuentes y producidos en distintos años del siglo XIX, lo que interesa abordar es la escenificación de un cuerpo atravesado por el discurso psiquiátrico. Revisando estas imágenes no desde una interpretación formalista de su configuración, sino más bien deteniéndonos en lo que ellas vehiculizan y lo que se escapa de las fórmulas de representación de la época.

Si consideramos el contexto de producción de estas imágenes aparece el papel del discurso del saber ocupando un lugar de dominio sobre lo registrado, parece recurrente el objetivo de constituir el cuerpo como escenario aislado, como expresión sintética de unos valores sobre la enfermedad que es la configuración discursiva que explica la locura. Invariantemente estos cuerpos se prestan como espacio en el cual escribir una mirada.

Es claro cómo para la medicina psiquiátrica del siglo XIX es necesario diseñar una "buena forma", una completud, una gestalt en la imagen que logre capturar el cuerpo como objeto, cuerpo sobre el cual se van a escribir unas retóricas particulares definidas casi siempre por el médico que a través de estos registros se pone en escena también pero de forma distinta, es él quien mide, descubre, nombra, su saber aparece allí como completo. La imagen se vuelve transparente, ella puede represenar la locura.

\section{El cuerpo experimental: el aura mística de la locura}

Durante los años 1852 a 1856 Duchenne de Boulogne, neurofisiólogo francés, condujo una serie de experimentos con la técnica de la "electrofisiología". Con la ayuda de un asistente conectaba electrodos a varios músculos faciales de sus sujetos experimentales. Luego, administraba descargas eléctricas de variada intensidad, lo que producía una contracción involuntaria de los músculos faciales. La fotografía le servía para inmortalizar el momento exacto de la descarga y de allí registrar la expresión facial producida, como una novedosa máquina de emociones. 
Imagen 1. Máquina de estimulación eléctrica Fuente: Guillaume Duchenne de Boulogne, 1861.

De l'electrisation localisée et de son application a la physiologie, a la pathologie et a la thérapeutique (2a ed.). París: Chez J.-B. Baillière.

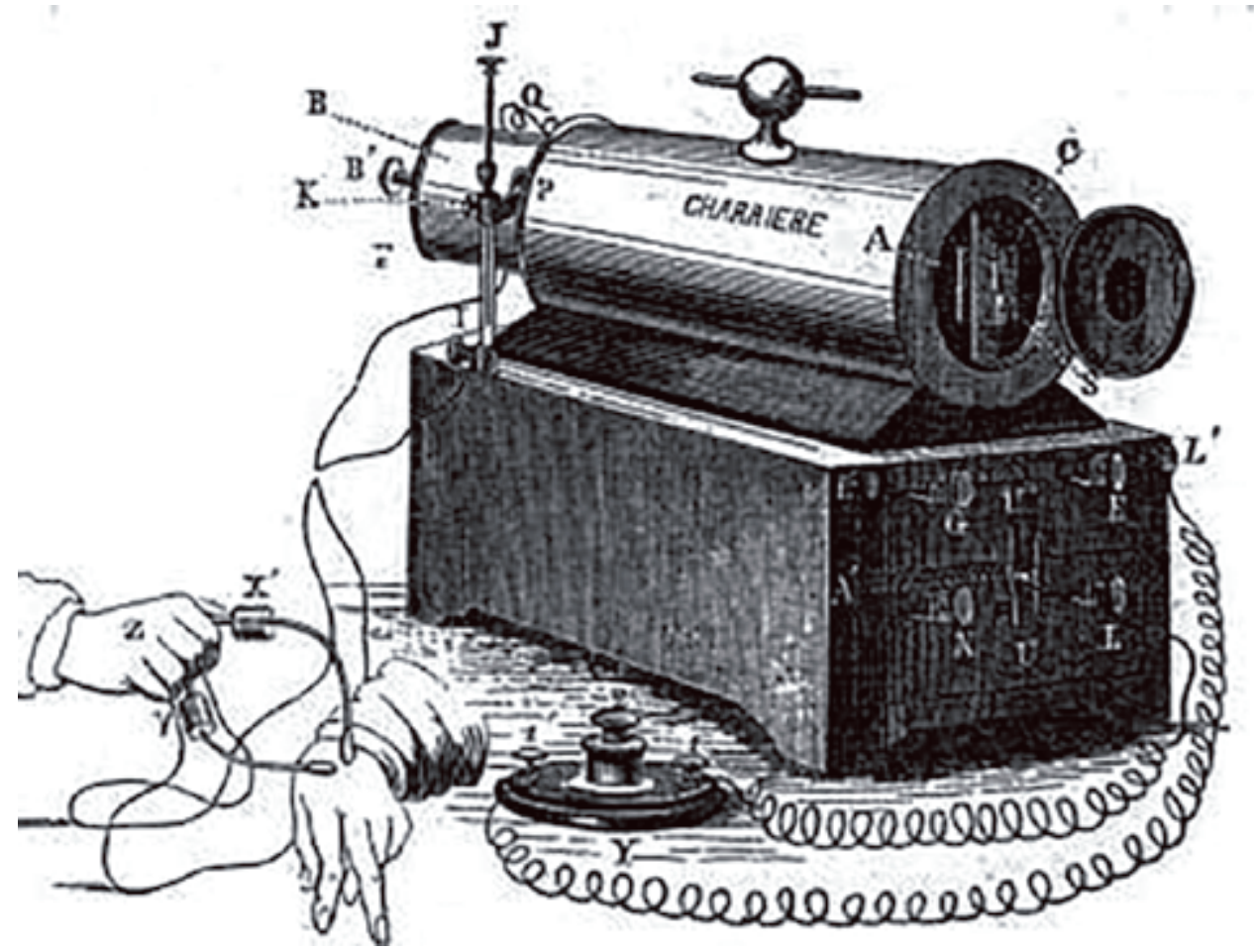

Duchenne trabajaba con el fotógrafo Adrien Tournachon, quien era el hermano de Félix Nadar, uno de los primeros practicantes de la fotografía en Francia. Sus sujetos eran pacientes del Hospital de la Salpêtrière en Paris, el libro de sus experimentos, Mecanismos de la Fisionomía Humana, fue publicado en 1862. En su trabajo se manifiesta la idea según la cual el acceso a la naturaleza era posible, sólo a través de un acceso visual a los objetos de estudio. Pareciera que el hecho de captar el instante técnicamente mediatizado pudiera funcionar como prueba de los fenómenos; se trata de una probatoria empírica, pero aplicada sobre el cuerpo, cosa que lo convierte de entrada en un objeto para ver, lo experimental se confundía con el espectáculo.

La tesis central del libro de Boulogne plantea que todas las expresiones faciales humanas resultaban de la acción de uno o un grupo específico de músculos. Su tesis consistía en emparentar las emociones humanas con la expresión del rostro. Es la misma época en que Darwin se ocupara de este asunto. De ese modo se argumentaba una causalidad metafísica en la expresión facial, lo que se planteaba era la posibilidad de que sus experimentos permitían hacer que el espíritu hablara. Claramente se dirige hacia un entendimiento de las pasiones por la "transfiguración del alma". La capacidad de reconocimiento de las emociones era un don dado por el "creador", de modo que la fotografía captaba una condición natural humana, pero de origen divino. 



Imagen 2. Mecanismo de la fisonomía humana Fuente: Guillaume Duchenne de Boulogne, 1862.

Mecanismo de la fisonomía humana, o análisis electrofisiológico de la expresión de las pasiones, por el doctor Duchenne de Boulogne. Con un atlas compuesto de 74 figuras electrofisiológicas fotografiadas. París: J. Renouard. 
Los registros fotográficos siguen una misma retórica, las distancias y planos no varían y se hacen con un único modelo, un cuerpo que adquiriría sentido por la intervención del saber médico. En ese sentido la aparición del médico en su papel como operador de los aparatos eléctricos sugiere un ordenamiento de poder por el saber que gobierna el cuerpo y lo moldea. La postura del cuerpo y su vestimenta sugieren un sujeto experimental desposeído donde pareciera ser necesario hacer énfasis en esta impropiedad constitutiva del enfermo. Ésta es probablemente una de las causas que provocan una suerte de atracción; el contemplar el cuerpo del enfermo en esa condición de puro objeto sobre el cual se aplica más que electricidad la violencia del discurso sobre un cuerpo a domesticar. La paradoja que se presenta es que mientras se hace énfasis en esa configuración objetiva aparece por completo una escenificación fantástica, es el punto donde la representación encuentra su ruptura, tambalea.

En el momento en que encontramos estas imágenes funcionando de modo anacrónico parece que algo del intento de representar la locura coincide con la fantasía y que en ese intento aparece la imagen como soporte que pueda dar una buena forma, una correspondencia punto por punto. La imagen fotográfica velaría lo que está por debajo de la representación, ¿qué es lo que se vela de la locura en las imágenes?, ¿qué puede ser lo que nos mira desde este lugar? Esta serie visual como un producto de época nos habla en un sentido de lo que se puede representar y sugiere en otro lo que oculta.

Para Duchenne de Boulogne las corrientes eléctricas sobre los músculos faciales abrían la ventana del espíritu, la expresión facial sería pura superficie hablante de la que es posible extraer de una medición técnica. En consecuencia el uso de la fotografía funciona para el experimento como un ornamento funcional a la idea de captar el tiempo y el objeto en su condición de manifestación de la locura. Produciendo series y repeticiones comparables, inicia como una forma de interés científico pero pasa del lado de lo fantástico, de la invención que llega a manifestarse en su aspecto más teatral. Se puede revisar en los textos que acompañan originalmente las fotografías, que evidentemente representar las emociones a través de estos experimentos tuvo que ver más con un interés estético y que el uso de fotografías en los ámbitos científicos de la época era pura cuestión de prestigio.
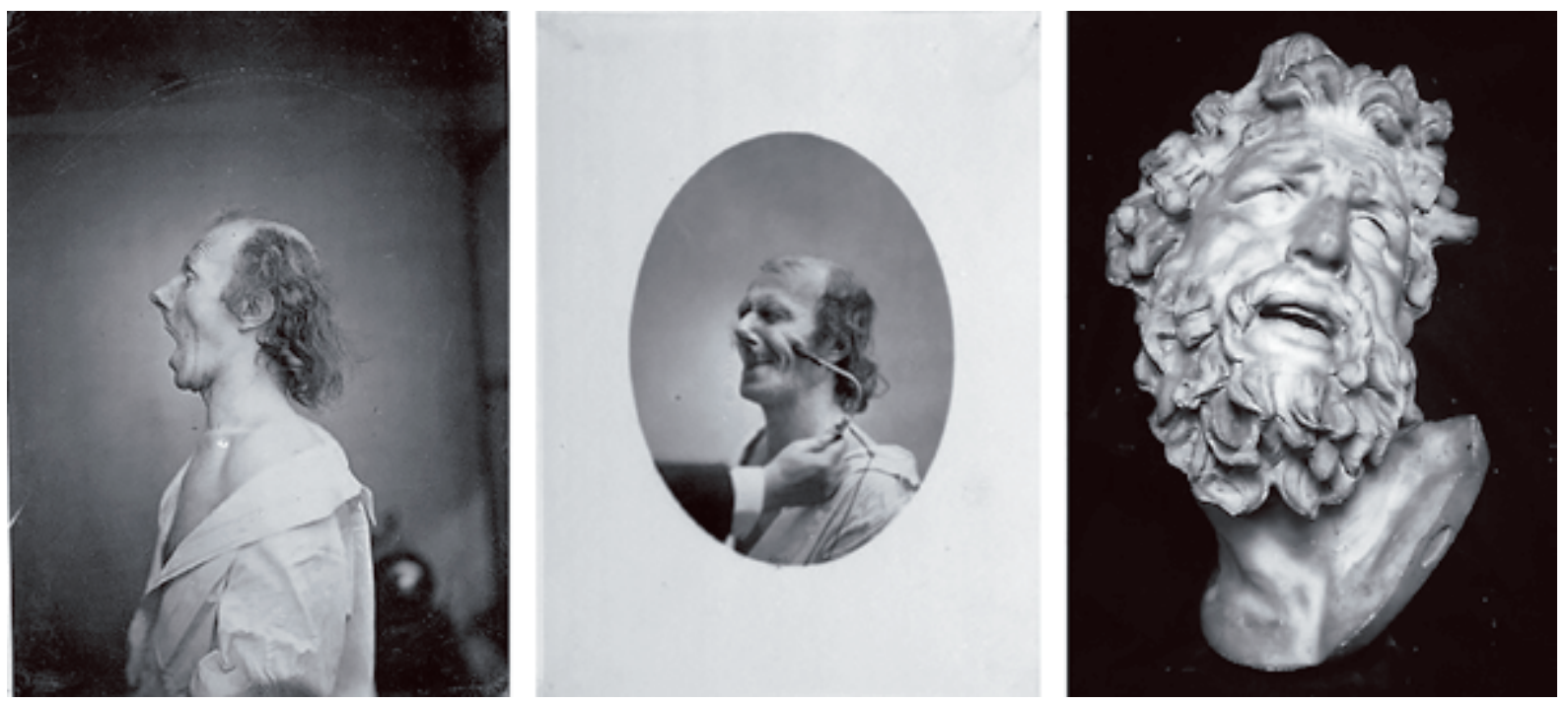

Imagen 3. Mecanismo de la fisonomía humana. Fuente: Guillaume Duchenne de Boulogne, 1862.

Mecanismo de la fisonomía humana, o análisis electrofisiológico de la expresión de las pasiones, por el doctor Duchenne de Boulogne. Con un atlas compuesto de 74 figuras electrofisiológicas fotografiadas. Paris: J. Renouard. 
Las tesis de Duchenne de Boulogne no tuvieron la resonancia esperada en los círcuitos académicos, dado que los estudios expuestos no tenían mucho apoyo científico, más bien su puesta en escena corresponde más a una cultura de la imagen, que liga lo estético con un estatus científico: lograr fotografiar el alma.

Mauro (2000) plantea cómo las referencias a un arte canónico, son fundamentales para justificar el uso de las técnicas fotográficas, el uso de fuertes luces es análogo al estilo de iluminación de Rembrandt. La alusión al trabajo y los cánones artísticos es una parte central de los argumentos de Duchenne para la validación científica de su experimento. También vinculaba algunas de sus imágenes con el estilo de otros pintores barrocos famosos incluyendo a Caravaggio y Jusepe de Ribera. Adicionalmente vinculaba su trabajo con la escultura Griega, refiriéndose especialmente al Laocôon (superior derecho) aplaudiendo el arte en este trabajo "apasionado de emociones sombrías" (Mauro, 2000, p. 4).

Sin embargo, Duchenne argumentaba que los errores en este tipo de representaciones del pasado, podrían ser corregidos con su técnica fotográfica absolutamente fiel. En el apartado de su libro "sección estética", lleva lejos este argumento. De hecho se plantea él mismo diseñar los cuadros para las tomas fotográficas. Situación que producirá las narrativas más barrocas y ficcionales en las imágenes. Con sus ambiciones artísticas en perspectiva, inicia la selecciónde pacientes mujeres que puedan ser fotografiadas, pues encuentra en las mujeres una mayor expresividad facial de la emoción. Esto llevará a ver localizado en el cuerpo femenino, distintos mitos científicos sobre la locura femenina, que alimentados por la literatura, empiezan a confundirse con nosologías clínicas. Duchenne lamenta la falta de inteligencia y capacidad de estas mujeres para efectuar las poses que él solicitaba, lo cual lo esforzaba a dirigirlas como maniquíes.

Las mujeres que aparecen en las fotografías caracterizaban personajes clásicos de la literatura universal como Lady Macbeth, quien sostiene un puñal, y dirige su mirada hacia fuera de la cámara, el médico, continúa sosteniendo su maquina de estimulación eléctrica. Las acciones representadas transportan un marcado componente misógino en el que las mujeres son títeres que completan el saber del médico, la teatralización del otro, se despliega a la manera de un espectáculo teatral, donde las figuras míticas, desde las cuales se ha interpretado la locura, se instalan, haciendo que la ficción y el experimento se confundan.
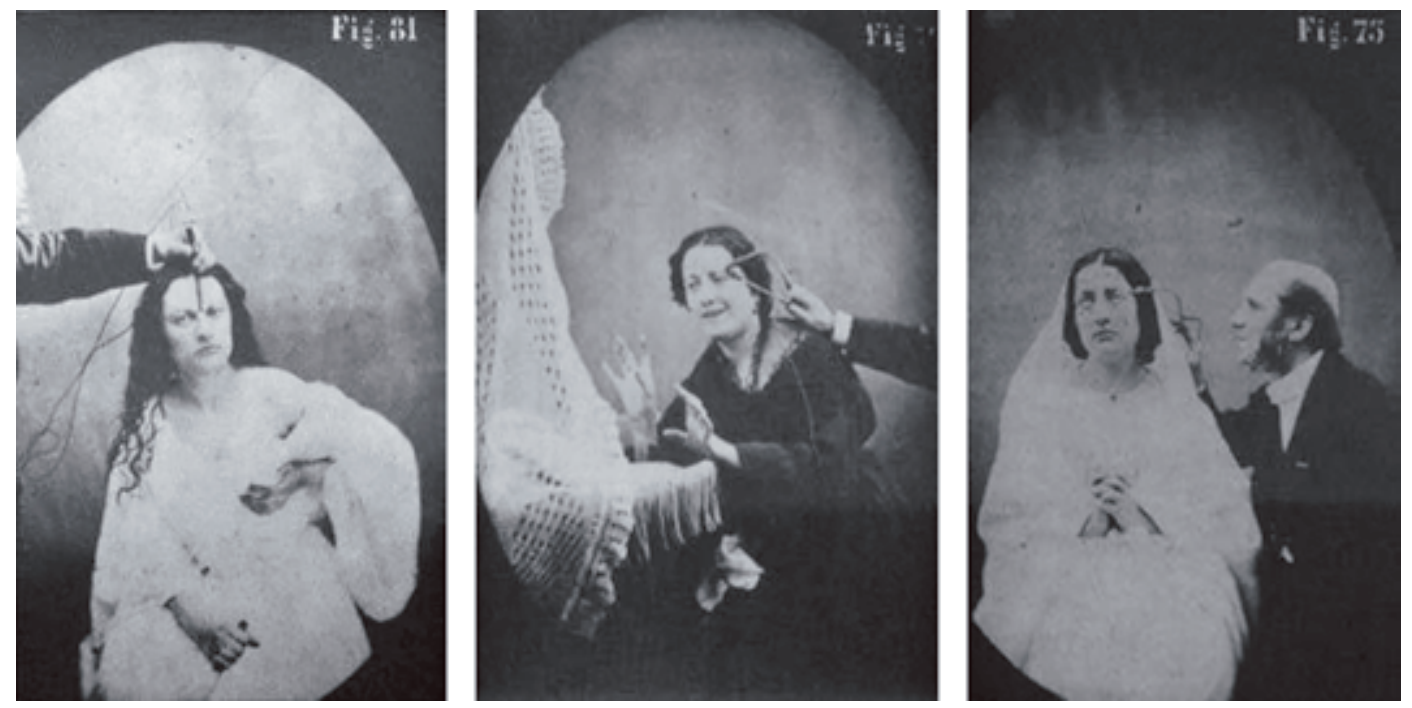

Imagen 4. Fotografías sin título sobre el mecanismo de la fisonomía humana

Fuente: Guillaume-Benjamin Duchenne de Boulogne, (1852-6), L'École Nationale Supérieure des Beaux Arts. 


\section{El cuerpo civilizado: retratos de la locura}

Este archivo fotográfico se produce en Pensilvania con una fecha aproximada de 1867 a 1875, constituye uno de los primeros registros fotográficos producidos como parte del inventario de una institución mental. Este álbum, encargado por Joseph Parrish quien era superintendente de la escuela en 1857 se originó en la Escuela de entrenamiento para niños y adultos débiles mentales en Pennsylvania y constituyó el primer trabajo fotográfico de pacientes mentales presentado como álbum en el siglo XIX, sin embargo no conocemos los datos de autoría de las imágenes ni tampoco de las personas retratadas.

Esta idea de álbum fotográfico fue tomada de los usos que empezaba a cumplir la fotografía al final del Siglo XIX, en donde se empieza a generalizar la fotografía del retrato individual y de grupos familiares, en este caso, el álbum funciona como souvenir que la institución produce para demostrar el trabajo que ha depositado en estos pacientes.
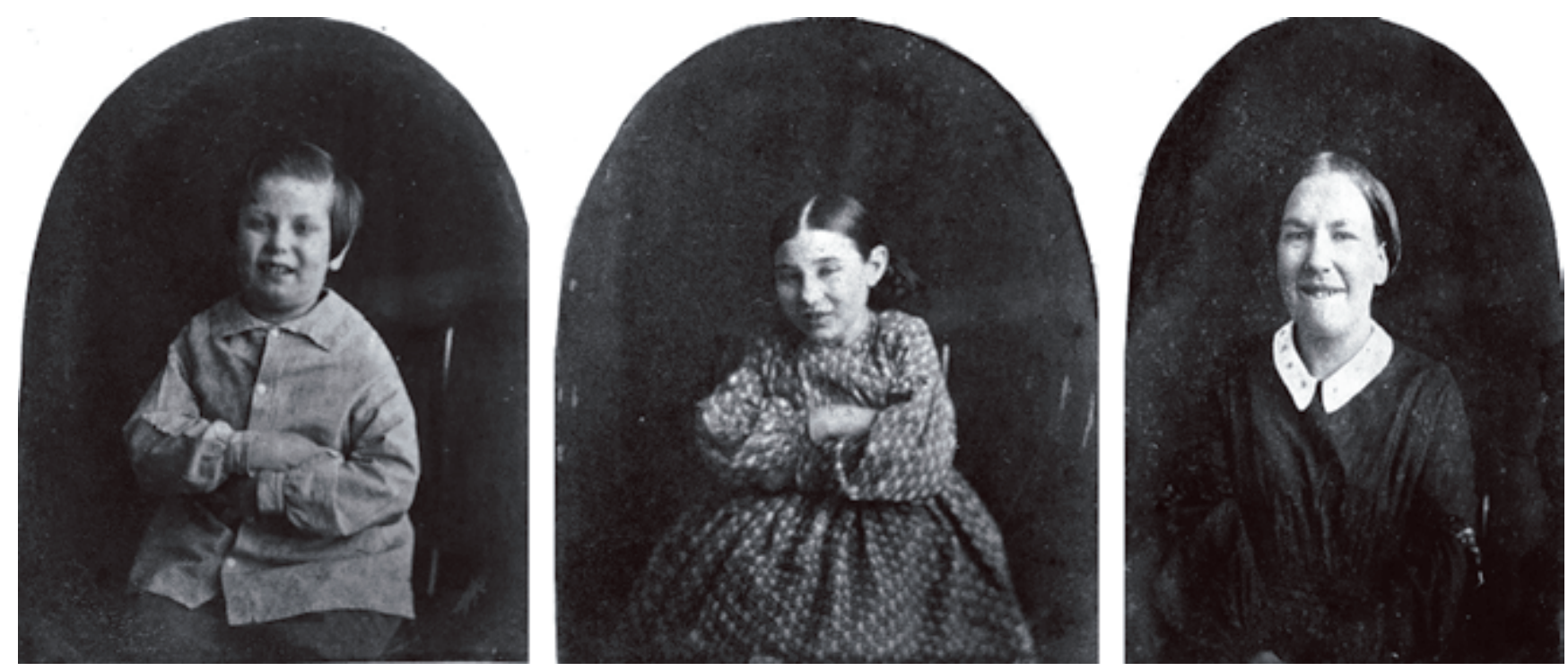

Imagen 5. Álbum fotográfico de la Escuela de entrenamiento para niños y adultos débiles mentales (ca. 1867-1875)

Aunque las fuentes y objetivos institucionales de este archivo no se encuentran determinados, interesa considerar las representaciones producidas sobre el cuerpo del loco como un cuerpo que es preciso presentar de manera pulcra y organizada, y que evoca por completo los usos retratísticos de la fotografía del siglo XIX. La mayoría de pacientes internados son niñas y niños, como también pacientes adultos sin empleo quienes se ocupaban de las tareas del campo. El trabajo en este contexto está por entero ligado a la idea de utilidad del enfermo como parte de su vida asilar. Se constata que la producción de este álbum fotográfico fue realizado con vestuario y escenarios decorativos, ya que se encuentra otro álbum: The mind unveiled, or: a brief history of twenty-two imbecile children publicado en 1858 que cuenta con la misma escenografía y retóricas en las poses que se solicitaban a los pacientes del archivo de Pensilvania. 
El agrupamiento de las imágenes corresponde a ligar estas retóricas recursivas como parte de un discurso médico que aparece aquí en su dimensión purificadora y progresista a través de la reforma por el encierro.

El ordenamiento de estos cuerpos sigue una lógica discursiva donde se evoca lo familiar, hay retratos en parejas separadas por sexo que se asemejan a las fotografías de retrato de hermanas y hermanos. Aparece un ideal de ordenamiento social que cuenta con unas normativas, proxemias y categorías producidas al interior del asilo, inspirada en los usos fotográficos en el ámbito familiar; esta "buena forma" de la organización social, elide en algún grado, lo inquietante de la expresión de las personas fotografiadas.

Señalando algunas retóricas de estas imágenes en términos de su construcción, podríamos pensar que existe una visión moral de reforma de la locura. Se puede entender esta cierta moralidad en el vestuario y en las poses: estas presentan cuerpos pulcros, bien peinados y organizados.

La escenografía utilizada puede decirnos mucho sobre los objetos, posturas y modos que representaban la idea de civilidad. Entonces encontramos nuevamente que la imagen funciona como conjunto completo que vehiculiza el significado, en este caso de la reforma mental, que se arma con todo un decorado que puede escenificar estructuras sociales idealizadas. La locura asociada a lo incorrecto, lo desordenado o lo inmoral, encuentra un equilibrio en esta escenificación, que podríamos decir no hace sino ocultar, sino velar lo que hay detrás, las fotografías tienen un carácter inquietante en el sentido de que nos devuelve una mirada, que ya ha sido posada sobre esos cuerpos.

Los pacientes así registrados entran como objeto de mirada de la fotografía que capta una ficticia realidad siguiendo los cánones estéticos de la época para hacer coincidir la reforma mental con los valores de la civilidad, como son el trabajo, la familia, la pulcritud. De todas maneras algo se escapa de este orden ideal, cuando las poses son notoriamente establecidas, la naturalidad o la correspondencia punto por punto de esta representación, se escapa.
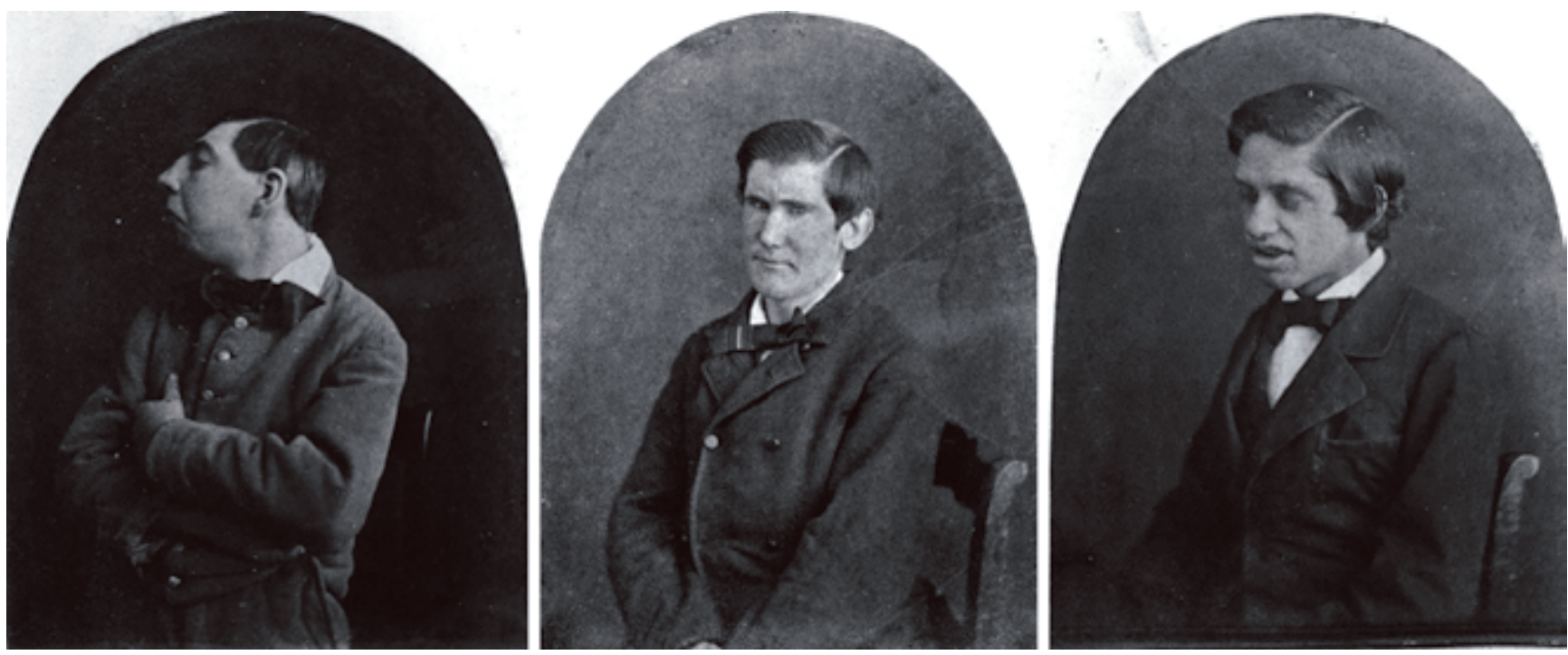

Imagen 6. Álbum fotográfico de la Escuela de entrenamiento para niños y adultos débiles mentales (ca. 1867-1875) 
Si bien, por una parte se representa la locura en un retrato individualizado, no se trata ya de las fotografías de retrato de la fisiognomía que buscaban tipos comparables de acuerdo a unos caracteres físicos, sino que se esboza aquí más el hecho de ser un caso, que presenta cada uno, un tipo de patología. Este registro hace parte de un funcionamiento institucional que necesita gestiona el archivo como evidencia, y por otra parte una institución encarnada en las identidades que produce. La ideología propia de las estructuras sociales de encierro se traduce en su intencionalidad de reformar los cuerpos, y encuentra en la fotografía una verdadera prueba con la cual puede legitimar su existencia. La fotografía posibilita la metáfora de una reincorporación de lo que es anormal, precisamente con los códigos de la normalidad.

Abajo en las tres fotografías de grupo, la imagen central es la idea de laboriosidad, la práctica de un oficio asegura el reemplazo de la vagancia o desocupación asociada a la locura, el retrato de la cotidianidad muestra esta vida apacible que proporciona la institución mental. Es la metáfora de una vida casi familiar como la representada en la retórica retratística del siglo XIX.
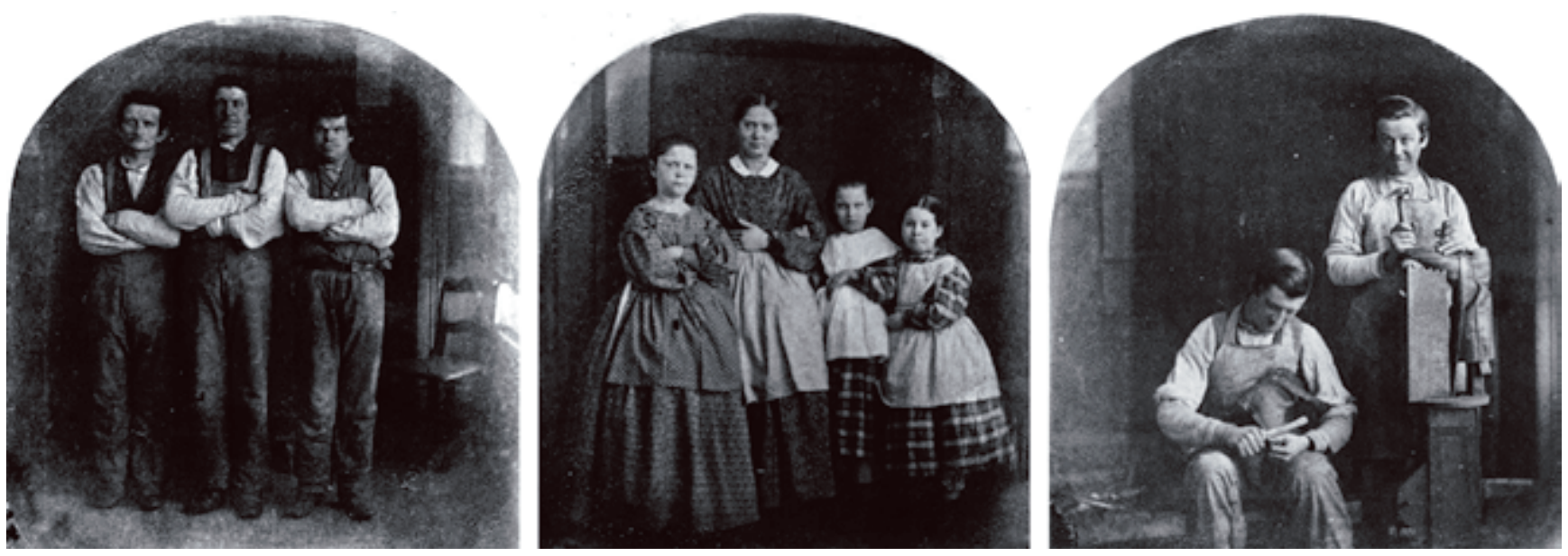

Imagen 7. Álbum fotográfico de la Escuela de entrenamiento para niños y adultos débiles mentales (ca. 1867-1875)

\section{El cuerpo teatral: la invención de la histeria}

Los documentos de la histeria ejemplifican una instancia donde el poder de la representación gestual es utilizado por los médicos en la producción de identidades y teatralidades. Charcot, psiquiatra francés que trabajara en el hospital de la Salpêtrière en Paris se dedicó a estudiar una enigmática enfermedad femenina del siglo XIX: la histeria. En el hospital habían casi 4.000 pacientes con las cuales puso en práctica sus teorías; En sus lecciones de los martes las pacientes eran exhibidas públicamente apelando a procedimientos experimentales, hipnosis, explicaciones fisiológicas, que hicieron famosos estas demostraciones que fueron consolidando casi como un espectáculo. 
El cuerpo de la histeria convulsionaba frente a la mirada médica que intentaba desentrañar su funcionamiento para llegar a un posible tratamiento. Demostraciones que tenían una clara vinculación con la representación teatral. Es este aspecto el que interesa destacar en su relación con la fotografía y la mirada. Justamente Charcot empieza a utilizar la cámara fotográfica en este intento científico de captar el tiempo del éxtasis, de la convulsión, del gran ataque histérico. Las poses que representaban estos ataques figuraban un cuerpo desdoblado, desposeído, en el que extrañas fuerzas lo movilizaban, similar a las ideas de siglos anteriores en los que se le atribuía a espíritus terribles la causa de la locura.

En esta versión demostrativa donde la ciencia por entero toma el lugar para explicar la locura estas atribuciones fantásticas de demonios y seres del más allá vienen a ser reemplazadas por la fidelidad de una mirada que se posa sobre el cuerpo interpretando una retórica de signos y síntomas, que se corresponden y materializan a través de prácticas y discursos frente al cuerpo femenino, la clínica del doctor Charcot se completaba por la presentación teatral de sus histéricas que se configuraban en imágenes idealizadas de lo que sería el gran ataque. La histérica en su papel de actriz vendría a ponerse frente a la mirada del auditorio que esperaba la aparición patológica.

Exorcizando los espíritus del cuerpo la fantasía médica resolvía por fin la dualidad del espíritu y la carne. Foucault puntualiza que el funcionamiento de la mirada médica viene a neutralizar esta operación de la imaginación que ha sido fuente y vehículo de los saberes sobre la naturaleza y los cuerpos, a favor de una descripción científico-racional donde ya no aparezca sujeto productor de conocimiento, sólo sujeto que ve y anota:

El vínculo fantástico del saber y del sufrimiento, lejos de haberse roto, se ha asegurado por una vía más compleja que la simple permeabilidad de las imaginaciones; la presencia de la enfermedad en el cuerpo, sus tensiones, sus quemaduras, el mundo sordo de las entrañas, todo el revés negro del cuerpo que tapizan largos sueños sin ojos son, a la vez, discutidos en su objetividad por el discurso reductor del médico y fundados como tantos objetos por su mirada positiva. (Foucault, 1964)

Con la fotografía la mirada encuentra el soporte mecánico que le permita ser aún más objetiva: era preciso generar entonces estas imágenes secuenciales, repetitivas, donde se podían seguir cuadro a cuadro el devenir del ataque, ese movimiento del cuerpo ante las cámaras se podía imaginar recorriendo el mosaico visual cumpliendo con el ideal científico de ampliar su ojo, hacerlo objetivo. Ante este ojo de mayor alcance aparece un escenario teatral donde se despliega la convulsión y el gran ataque histérico, como puro acto simulatorio, como exhibición. La técnica fotográfica que da muerte al tiempo y captura la esencia de las cosas parecía ser el aparato mágico, el instrumento perfecto que esperaba la mirada médica para avanzar sobre el cuerpo y por fin captarlo.

Foucault conceptualiza esta arqueología de la mirada que confía y posa su creencia en la evidencia. Esto se corresponde exactamente en un punto fundamental con las ideas de la psiquiatría del siglo XIX, porque transporta el idealismo empírico de la ciencia que extrae la verdad de las formas, y en relación a un objeto irrepresentable por definición había sido la locura.

Albert Londe (1858-1917), uno de los más influyentes fotógrafos de la Salpêtrière, afirma en las siguientes líneas que el valor de previsión de la fotografía se debe a su sensibilidad: 
Sabemos que la placa fotográfica no es sensible a los mismos rayos que nuestra retina: así pues, podrá, en ciertos casos, mostrarnos más que el ojo, revelarnos aquello que éste no es capaz de percibir. Esta sensibilidad particular cobra un valor muy especial y no es, en mi opinión, la propiedad menos importante de la fotografía.

Imagen 8. André Brouillet, 1887. Una lección sobre histeria por Jean Martin Charcot.

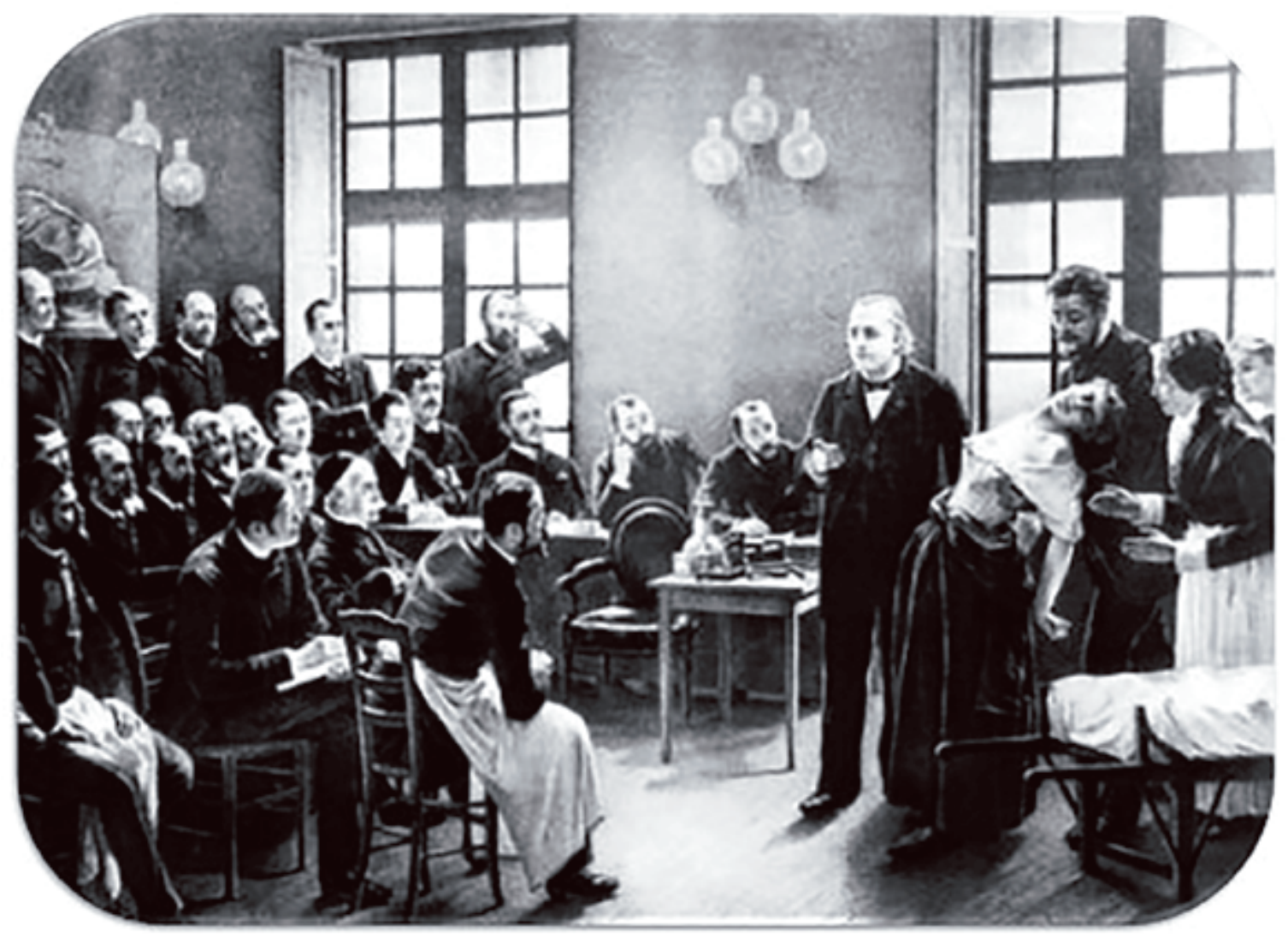

Es preciso reparar en lo que el artificio técnico define frente a la representación; en el caso de la fotografía de la histeria, los largos tiempos de exposición que en ese momento se requerían para captar el presente de la convulsión, no hubieran podido registrarse sin una suerte de escena y tiempo perfecto representado por una intérprete, una suerte de complicidad mediada por la mirada entre médico y paciente. 

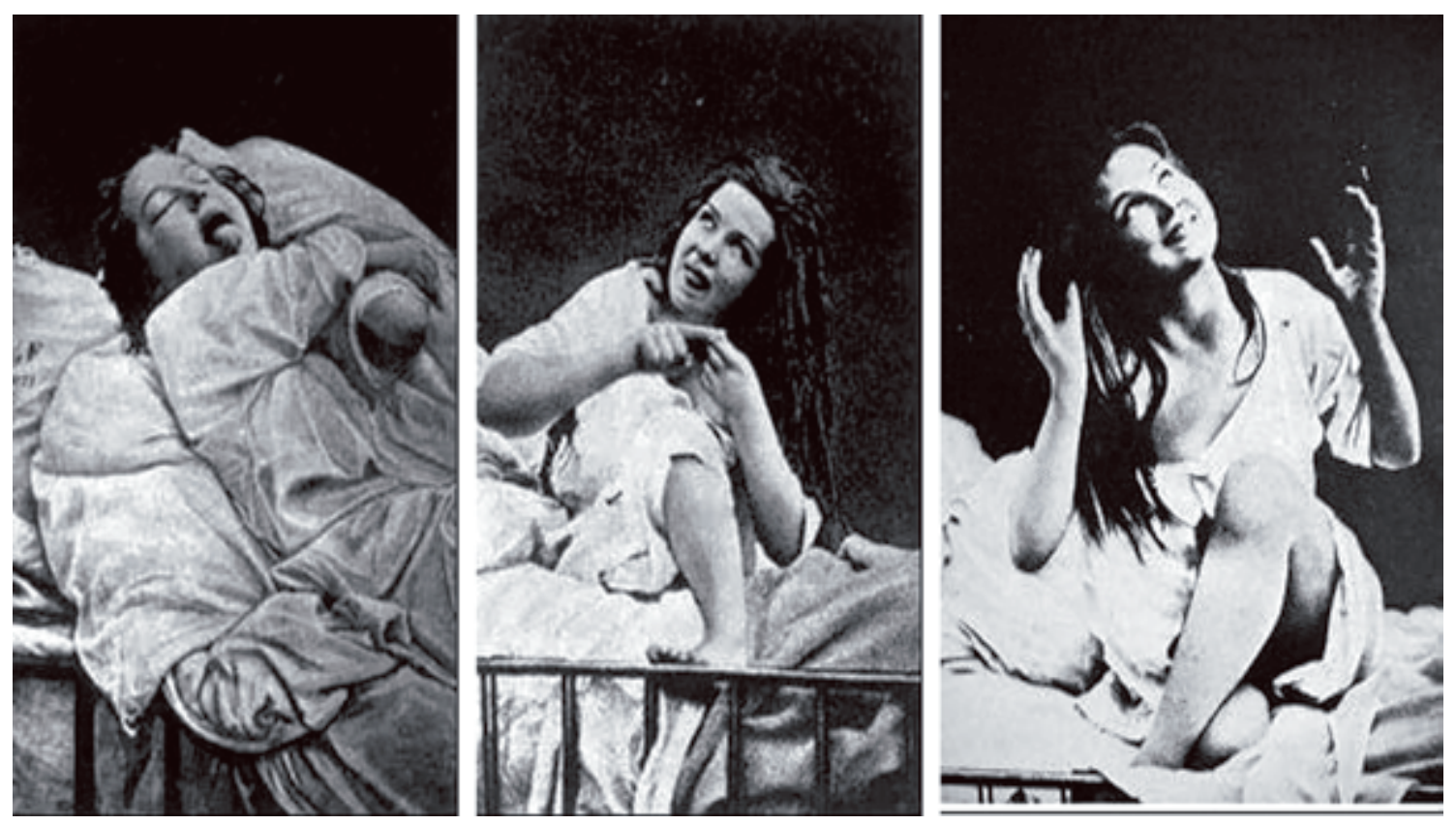

Imagen 9. Fotografías de la histeria Fuente: D. M. Bourneville y P. Regnard. 1878.

Iconographie photographique de la Salpêtriere. París: Progrès médical, A. Delahaye.

Las ideas de Charcot promovieron en la época, la identificación de las alteraciones del funcionamiento cerebral mediante una sintomatología corporal, es una clínica basada en la imagen que en este caso las histéricas desplegaron. La búsqueda de capturar lo invisible, llega al planteamiento de que por medio de una larga exposición a la placa fotográfica, se podría incluso captar el aura o mundo pasional del fotografiado, captar las facies, que es la expresión particular de un tipo patología mental, se asumía como registro directo del alma.

La dualidad metafísica que representa el binomio alma-cuerpo, que atraviesa toda esta visión sobre la enfermedad mental, se sustenta a través de la fotografía al intentar representar este universo íntimo llamado alma, aura o espíritu. Al lograr detener esta instancia invisible, a través de la imagen, quedan suspendidas las representaciones pictoricas sobre la locura que ocupaba a los artistas durante siglos.

El historiador del arte George Didi-Huberman, con su trabajo, La invención de la histeria: iconografía fotográfica de la Salpêtrière, demuestra que este carácter ficcional de la histeria, al convertirse en objeto de la representación, abre una desconfianza fundamental sobre I a-imagen y la representación, no podríamos confiar en la visión, ni en la imagen, ni en la representación.

En el artículo Crítica y clínica: la invención de la imagen como histeria, Jaime Repollés (2008) comenta que el trabajo de Didi-Huberman logra develar los cortinajes científicos de este obsceno gabinete de curiosidades donde el arte de maquillar la ciencia con la apariencia dio sus más crueles y fascinantes resultados. La Histeria se convierte así en la obra maestra de la mirada médica. La iconografía clínica se construye entonces con la utilización de múltiples montajes, vestuarios, iluminación, y con los cánones clásicos de la representación plástica. 
Muchos son los ejemplos de esta supuesta mecanización de los cuerpos como máquinas visuales del alma durante las vanguardias históricas; arlequines y muñecas de compañía, pierrots, saltimbanquis y sonámbulos constituyen la inmensa iconografía del «autómata espiritual»: un cuerpo reducido a movimientos mecánicos por una suerte de suspensión de la conciencia.

Si planteamos que el ojo de la ciencia se cree portador de la mirada, tendremos que convocar el sujeto del inconsciente al que la mirada se le escapa. La idea de poder captar la imagen de la locura con la ilustración científica pudo verse como la conquista de esa alma ingobernable que seduce a caer en la creencia de la representación.

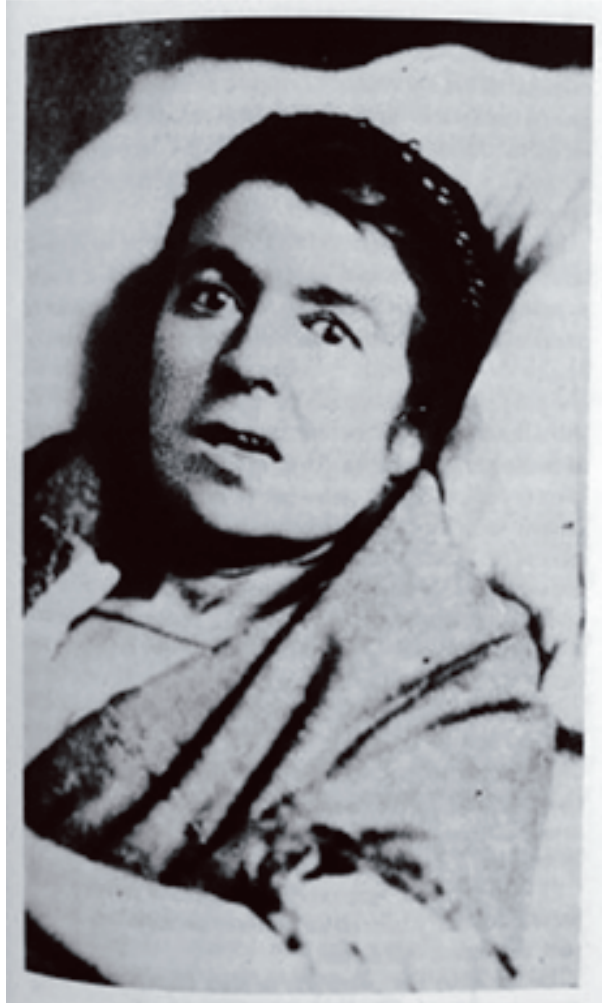

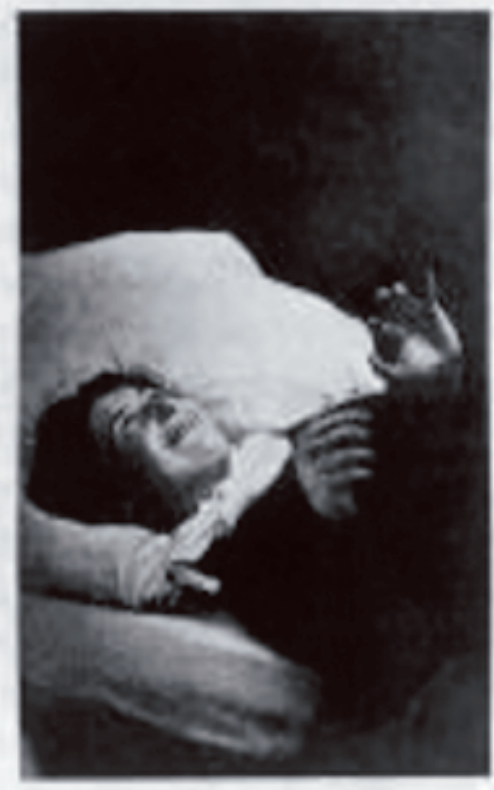

The $x \times 1 \times 4$

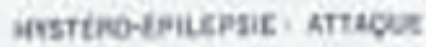
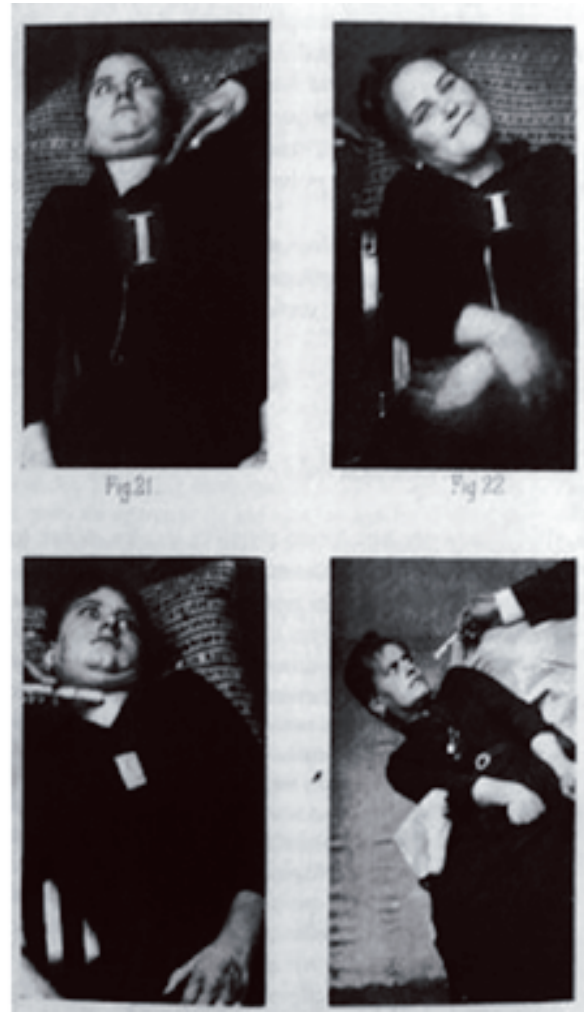

Imagen 10. Fotografías de la Salpêtriere

Fuente: D. M. Bourneville y P. Regnard, 1878.

Iconographie photographique de la Salpêtriere. París: Progrès médical, A. Delahaye. 


\section{Referencias}

Didi-Huberman, G. (2006). Ante el tiempo: Historia del arte y anacronismo de las imágenes. Buenos Aires: Adriana Hidalgo editora. (Trabajo original en francés: Devant le temps Histoire de l'art et anachronisme des images. Les Editions de Minuit).

Foucault, M. (1971). Las palabras y las cosas. México: Siglo XXI.

Foucault, M. (1997). Historia de la locura en la época clásica. Parte III. México D. F.: Fondo de Cultura Económica.

Jackson, M. (1995). Images of deviance: Visual representations of mental defectives in early twentieth-century medical texts. Cambridge University Press on behalf of The British Society for the History of science. Tomado de: The British Journal for the History of Science, 28 (3), pp. 319-337.

Mauro, P. (2000). Duchenne: Discourses of Aesthetics, Sexuality and Power in Nineteenth-Century Medical Photography. París: Athanor 18.

Repollés, J. (2008). Crítica y clínica: la invención de la imagen como histeria. Enlaces: revista del CES Felipe II, 8. Recuperado de http://dialnet.unirioja.es/servlet/articulo?codigo=2578673

\section{Recursos en internet}

ASCLEPIO. Revista historia de la Medicina y la Ciencia. ISSN. 0210-4466. En línea: http://asclepio.revistas.csic.es/index.php/asclepio/ issue/archive

Base de datos: Image from the history of medicine. En línea: http://ihm.nlm.nih.gov/luna/servlet/view/all

Bases de datos de imágenes: Cat'zArts. Beaux-arts de Paris, l'école nationale supérieure. En línea: http://www.ensba.fr/ow2/cat-

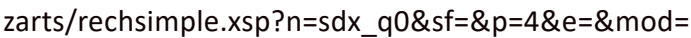

Colecciones patrimoniales de museos de Francia. Imágenes digitalizadas. En línea: http://www.ensba.fr/patrimoine/collections. htm\#Catalogues

Círculo de bellas artes de Madrid: http://www.circulobellasartes.com

Museo de arte contemporáneo de Nueva York. Moma. http://www.moma.org/

Revista digital Representations (blog de divulgación). En línea: http://www.representations.org/

Revista trimestral de Arte y Cultura. En línea: http://www.exitmail.net/exitmail.php?idart=624

Revista Studio Visual Marketing. En línea: http://estudiosvisuales.net/revista/index.htm 